\title{
FISCAL ASPECTS OF METROPOLITAN REGIONAL DEVELOPMENT
}

\section{Mabel Walker $\dagger$}

Metropolis is a figure of speech. It is not a unit of government, but a concept that is foggy in spots and fuzzy around the edges. Definitions have been offered and are being utilized currently, but they are not completely satisfactory. Nevertheless, while we grope for satisfactory definitions and interpretations, an acute problem exists which we variously designate as metropolitanism, urbanization or decentralization. It challenges the best thinking of our time in many different branches of learning.

It is the underlying thesis of this paper that there is no reasonable expectation that the problems of adequate financing for local government services can be either fully or permanently solved through governmental reorganization, whether that takes the form of annexation, consolidation or a new super unit of local government imposed on a metropolitan or regional basis.

Progress can, and undoubtedly will, be made along all of these lines, so that here and there, and for temporary periods, the situation will be considerably ameliorated. But the current and potential forces of technological, economic and sociological change are so dynamic that the governmental scientists and reformers will not be able to devise and bring into existence new patterns of government that will be comparable in stability and permanence to those that have existed in the past. There has been a great increase in the rate of depreciation and obsolescence on governmental structures as well as on industrial machines and business techniques.

This will be particularly true if those who are trying to devise the new patterns simplify the current metamorphosis merely in terms of increasing urbanization. The so-called urbanization appears paradoxically to be resulting partly from the outward push of the population away from congested urban centers, and even from smaller centers, and partly from the tremendous spurt in population growth. As the city residents push out from the center of the city they tend to engulf

$\dagger$ Executive Director, Tax Institute, Inc., Princeton, New Jersey. A.B., 1926, Barnard College; Ph.D., 1930, Johns Hopkins University. 
the surrounding small communities and to bring them rapidly within the urban definition, so that persons who have clung to their rural homes suddenly find themselves surrounded by persons trying to escape the city and both groups thus unwillingly contribute to urbanization.

Something much more complex and pervasive than urbanization, or even metropolitanization, is taking place and it is affecting rural as well as urban and suburban life. The pattern of living becomes increasingly interrelated and confused in the rural as in the more congested regions.

Moreover, complicating even further these various interlacing relationships of communities of all sizes, has been the emergence in the last few years of a new pattern of development along functional lines. The residential development has been manifest for several decades, but now there are developments for industrial purposes, known as industrial parks or industrial centers, developments for merchandising, known as regional shopping centers, and other developments for specific functions, such as research or some other purpose.

The phenomena of current economic developments, patterns in land use, population patterns and fractionated governments will be treated by other contributors and can be passed over here.

\section{Nature of Impact of Local Fiscal Problems}

Against this dynamic and fluctuating background it is necessary to devise a revenue system that will provide essential governmental services for fringe areas as well as for central cities. Not only does a revenue system have to be devised to conform to this amorphous pattern, but it also has to be one that is carefully designed to avoid accelerating trends that appear to be undesirable, or that would be undesirable if they took place too rapidly. Every local revenue proposal must, therefore, be subjected to searching scrutiny to insure that it will not have adverse effects. Conversely, any fiscal measure that would serve to lessen present difficulties should be given serious consideration.

In short, in addition to considering such standard revenue criteria as equity, adequacy and administrative feasibility, careful consideration must be given to the economic, sociological and political effects of the tax or the service charge. For example, if a tax which could be justified according to other criteria should appear to be one which would tend to bring about, or to hasten, the exodus of industry and trade from the central city, or if it would affect living and travel habits in a way that would be adverse to the city's interests, or if it would strengthen political resistance to desirable reorganization of governmental units, it might be dubious wisdom to enact it into law. 
Since essential governmental services transcend governmental boundary lines, in what way can the necessary revenues for such services be secured? Answering this question necessitates an examination of the points of current stress and strain, both with respect to units of government and governmental functions. Both core cities and fringe areas ${ }^{1}$ are experiencing fiscal difficulties. The core cities are losing tax potential as relatively higher income groups move out and tend to be supplanted, if at all, by relatively lower income groups, and also as industry and retail trade tend to move from the central city to the fringe areas. Notwithstanding these losses, the costs of running the central city tend to increase. The central city frequently becomes heavily involved in mass transportation difficulties, street widening and provision of various other traffic facilities, as well as continuance and perhaps expansion of governmental services, which are utilized not only by the resident population but also by the rapidly growing commuter and contact groups. ${ }^{2}$

At the same time, fringe areas experience difficult fiscal problems that frequently outpace any new revenue sources. The new communities are suddenly confronted with heavy capital costs for street and highway construction, water supply, sewerage facilities and school buildings; operating costs are also rapidly increased.

How should this problem be approached? Shall it be from the standpoint of developing the structure of the revenue system by units of government, by functions, or by previously accepted principles of taxation? A cursory examination of the problem shows that none of these approaches is feasible. Clearly not every governmental unit as now constituted can raise sufficient revenue from its citizens to support local functions, and the smaller the area the less likely it is to do so. This is true even with liberal amounts of state aid.

Nor can every function pay its own way. This is particularly true of the most costly of all local functions-education. The strength of the United States has stemmed largely from the realization, from the beginning of our national life, that it is essential in a democracy to have a literate electorate and that the attainment of that goal must be achieved mainly at public expense. Relief and other welfare activities are obviously other functions that cannot pay their own way.

1. The use of such terms as central or core cities and fringe areas is obviously an extreme oversimplification in connection with the New York region and is not adequate for many other urban regions. Since no attempt is being made here to deal with any particular region, the term fringe area is used loosely to denote satellite cities and suburban fringes, whether incorporated or unincorporated. The attempt is merely to deal with general principles in approaching local fiscal problems.

2 . The latter term is being used to designate persons who do not commute to the city, but who visit it frequently for business, shopping, recreation, education, cultural or other reasons. 
Similarly, local taxes cannot be based entirely on the benefits-received or the costs-incurred principles of taxation-for the reasons just stated. Some of the most essential functions are for the benefit of those persons who can pay little or nothing for them.

The ability-to-pay principle must also be rejected as the sole basis of local taxation, at least if, as is usual, the term is understood to refer to graduated taxes. If local taxes were based entirely, or even to a large extent on the so-called ability-to-pay taxes, that is, graduated income and death taxes, the result would be to drive much taxpaying potential out of the community.

If we are thus stymied in four major directions in our attempts to establish a local fiscal structure, and so cannot set it up on either a governmental or functional basis, or on either the principle of ability to pay or of benefits received, how can we logically proceed to devise a method of financing governmental services in regional areas? The situation is complex and it calls for a more complex yardstick than any of the previously mentioned ones.

Since a large part of the cost of government-particularly in the central cities-is expended in providing services for non-residents, a partial solution to the problem may be realized by attempting to tax insofar as possible the persons who benefit, for the services from which they benefit, whether or not they live within the taxing unit. ${ }^{3}$ Much agonizing consideration currently is being given to the problem of solving intergovernmental fiscal problems on the local level. For example, if rapid transit is necessary for persons commuting from the fringe governmental units, how can those units be made to pay part of the cost of providing such service? Efforts in this direction have to date been rather bungling because the effort has been directed toward getting the revenue from. the fringe governments. An equitable solution of this problem appears impossible when we approach it from the standpoint of intergovernmental agreements among a great number of local governments. Even if dozens or hundreds of satellite governments could agree with the central city on a method of sharing the costs, it is still doubtful that substantial equity would be achieved. Since in some, perhaps most, of these units only a portion of the citizens would benefit, it would be difficult to devise an equitable basis within a single area, even after agreement had been reached among the different units.

3. This is not to be interpreted as advocacy of having all governmental services paid for on a benefit basis, particularly in the case of individuals, but rather as an attempt to achieve greater equity in paying for governmental services as between persons in different governmental areas. 
Much of this problem disappears if we concentrate attention on persons instead of governments. Tax devices that would enable the central city to tax directly commuter and contact population appear to offer one of the most equitable approaches to the problem of getting financial support for the central city, which is providing governmental services not only to its resident population but also to the far larger commuter and contact population.

Where can the essential revenues be obtained in this complex state of affairs? The sources of revenue that appear most promising in view of the various complexities and requirements are the property tax, the flat-rate income tax, intergovernmental service charges for water, sewerage and some other services, and a motorist's urban privilege tax. All but the last named are already being used to some extent, and a specific tax on urban motorists is beginning to be advocated.

\section{The Property Tax}

The property tax is the time-honored major source of local revenue. It will probably continue to be such, both for central and fringe units of government. Nevertheless, the time seems ripe for a critical re-examination of the property tax, both with respect to role and administration.

The property tax in most states rests upon two bases: real estate and personal property. Two or three states, however, have eliminated, or almost eliminated, the taxation of personal property, both tangible and intangible. A number of other states have eliminated the tax on certain categories of personal property, or have subjected them to differential rates of taxation. The defects of personal property taxation, both with respect to equity and administrability, have been fully set forth in tax literature for some decades. A definite long-term trend toward the erosion of the personal property tax-although a very gradual one-seems evident, so there seems little reason to anticipate any greater, or even as great, reliance on this tax.

The situation is quite different with respect to the real property tax, which falls upon land and buildings. Although the proportion of local revenues derived from real estate taxation has diminished during recent decades, and will probably continue to shrink somewhat, there appears every reason to believe that both urban and rural local governments will continue indefinitely to derive a substantial part of their revenues from real estate taxation.

But in the face of the dynamic changes that are taking place with respect to the utilization of land in central city, suburban and fringe areas, equitable assessment becomes more than ever a matter of prime 
urgency. Not only will grave injustice be done if assessments do not reflect the actual market value, as closely as is humanly possible, but the forces making for disintegration of the central city and indeed of the satellite cities may be greatly accelerated if properties are overassessed or if they are unevenly assessed. On the other hand, underassessment will deprive the government of sorely needed revenues.

Utilization of outlying properties may likewise be distorted if assessments are not equitable. Moreover, if in small communities assessments are inordinately low because of the chance location of industrial or business enterprises, or extraordinarily high because of the absence of such enterprises, or because of substantial amounts of exempt property, injustice will be done and appropriate utilization of the land may also be affected.

Although assessment constitutes the greatest difficulty in property tax administration, collection procedures are also of great importance. Moreover, in connection with the property tax, it is important not only that administrative techniques and standards be of a high order but also that, in determining the rate, due consideration be given to economic and sociological effects.

It may very well be that substantially increased revenues can be obtained from the property tax through better administration and even that increased revenue may be safely derived therefrom in certain communities through increased tax rates, but the determination of the rates should be on the basis of the fullest possible understanding of the local economic trends and the probable effect of the tax rate upon such trends.

So far as central cities are concerned, it is likely that if there is to be increased revenue from the property tax, it must be found through better administration rather than through increased rates or a general upward revision of assessments due to increased land values. The rapidly growing suburban and fringe areas may, however, find it possible to get more revenue as a result of all three possibilities: improved administration, increased land values and increased tax rates. The second possibility will result from the economic development of the community, and the third from the fact that tax rates in more highly developed communities, with their normally higher standards of governmental service, are usually higher than in the more rural areas which offer less service.

In spite of these possibilities, there seems no reason to anticipate that the real estate tax will increase in relative importance, or even that it will hold its own relatively. It may be a wholesome thing that this is true because in recent years there has appeared to be an increas- 
ing tendency to evaluate all forms of local growth and development in terms of property tax yields. Careful studies are made in order to ascertain at just what figure a new home must be valued in order to offset the cost of educating one child. Other painstaking studies are made of various types of business enterprise and the exact extent to which they result in a deficit or profit to the local community.

The New York Times of November 30, 1956, carried two items reflecting this viewpoint. New Canaan, Connecticut, has increased minimum building sites from two to four acres in the northern part of the community and from one to two acres in the southern part. The zoning commission "received its backing mainly from the newer residents, many of them commuters. They felt that tighter regulations were needed to prevent an increase in tax rates, overcrowding in the schools and a general invasion of 'privacy.' " It was also indicated that the restrictions would do much toward solving water supply problems. $^{4}$

The other item emanated from Rochester, New York, where the president of the New York State Home Builders Association suggested that the minimum size of suburban lots be reduced to enable families of modest means to purchase homes, and complained about the "suburban snobbishness" of local boards.

A new type of social segregation is developing in many communities, which affects segregation along income and age lines, rather than by social status or race. Such restrictions bring about a considerable measure of segregation by age, because of the more limited incomes of the younger families. "Our children can no longer afford to live in the same communities with their parents," some mature and prosperous Westchester residents were heard to complain. We are, therefore, getting a new type of social stratification, and it appears to be partly due to the property tax. So we get the immature young Levittowns, on the one hand, and the static and fossilized communities of mature citizens on the other.

To what extremes can we go in denying habitation within a community to certain groups because they do not pay their way on a property-tax basis of local financing?

The persons who benefit most from taxes are those who pay no taxes at all-as, for example, the impoverished orphan who is fed, clothed, housed, protected and educated at public expense-and the public conscience of today would not have it otherwise. We certainly

4. N.Y. Times, Nov. 30,1956, p. 25 , col. 8 .

5. Id. col. 7. 
do not desire a fiscal system whereby governmental services are doled out only to those individuals who pay taxes and only in proportion to what they pay. Yet in some of the local finance discussions where attention is focused upon the property tax as the source of local revenue, the desirability of a new residential development, a new industrial enterprise or some other new development, appears to hinge on whether it will pay enough property tax to offset the cost of the local government services it will receive.

Yet it is theoretically possible for a community to thrive without any property taxes at all. It has happened in some small areas. Two considerations should enter into our evaluation of the economic contribution of a particular component of the community. First, the area under consideration should not be so small as to be lopsided from an economic and social point of view. In a healthy well-rounded community, whether it be large or small, it is almost as illogical to segregate one small bit and ask if it is paying its way, as to evaluate similarly each portion of the human anatomy. We do not ask if the right hand or the left foot is carrying its full responsibility. The body is an integrated whole, although some parts are more vital than others. When growth of any part becomes abnormal, drastic remedies must of course be sought.

Second, it is no longer necessary to evaluate each component element of the urban body solely in terms of the property tax. The property tax is important. It will continue to be important. But it is no longer the whole story of local finance.

\section{The Local Income Tax}

The cities started breaking away from extreme reliance on the property tax during the thirties. New York City, with its adoption of a retail sales tax in 1934, and Philadelphia, with its adoption of a local income tax in 1939, took on the role of bellwethers for American cities.

The local income tax is the most important of the local nonproperty taxes from the standpoint of productivity. Although the total yield from local income taxes in 1955 was less than from local sales or gross receipts taxes, this was because three or four times as many cities imposed the latter. Moreover, the local income tax is the only tax that can be expected to produce large amounts of revenue from the nonresident, since it reaches the commuter who works in the city.

It has been estimated that fifteen per cent of $\$ 48.8$ million obtained. from the Philadelphia tax in 1954 came from approximately 90,000 
daily commuters. In St. Louis the nonresident contribution amounted to about twenty-five per cent of the yield. In Cincinnati it was seventeen per cent, in Dayton twenty per cent, and in Pittsburgh ten per cent. ${ }^{6}$ The local income tax also measures up to the criteria of administrative feasibility, equity, and innocuity. There is opposition to it from several directions, particularly from those persons who have developed an allergy to income taxes at one extreme and those who insist upon graduated taxes at the other. Nevertheless, there are certain inexorable developments that will probably lead to fairly widespread adoption of the income tax in large cities.

Flat-rate income taxes on earned income and net profits are now imposed in twenty-seven cities of 25,000 or over and in a number of smaller communities. In Pennsylvania only the net profits of unincorporated businesses are taxed by the cities. The local income tax is most widely used in Pennsylvania. Eighteen cities, 117 boroughs, 16 townships, and 252 school districts impose such taxes. All of these taxes, except the one in Philadelphia, are imposed under the famous Act 481, " or "The Tax Anything Law," whereby the state gives local units power to tax anything not taxed by the state.

One per cent municipal income taxes were proposed in 1956 by special tax committees in Kansas City, Missouri, and Milwaukee, and a North Carolina tax study commission has recommended that cities be authorized to impose a payroll tax.

The following table indicates the current rates of the more important local income taxes and the year in which the city first imposed an income tax.

There are serious objections to the income tax for smaller units of government, but for the larger central cities it offers an equitable, productive and administratively feasible source of revenue. Further, it offers the very great advantage of enabling the city to derive some revenue from nonresidents who earn income in the city.

\section{Intergovernmental Service Charges}

The more acute problems in the fringe areas center around unregulated use of land, water supply, sewage disposal, police protection and transportation and traffic.

The spread of built-up areas respects no governmental boundary lines. Developments overrun municipal, township, county and even state lines in a wholly erratic manner. Nevertheless, as development

6. Sigafoos, The Municipal Income Tax 78 (1955).

7. Pa. Stat. AnN. tit. 53, § 2015.1 (Purdon Supp. 1955). 
Income Taxes in Cities of 25,000 Population or Over

Kentucky:
City
First Year Imposed
Current Rate

Lexington

Louisville

1952

Newport

Paducah

1948

1952

1950

Missouri :

St. Louis

1948

Ohio:

Barberton 1954

Cincinnati 1954

Columbus 1947

Dayton 1949

Norwood 1954

Springfield 1948

Toledo 1946

Warren 1952

Youngstown 1948

Pennsylvania:

Aliquippa $\quad 1948$

Altoona 1948

Erie 1949

Johnstown 1948

Mount Lebanon Township 1954

New Castle 1949

New Kensington 1954

Penn Township 1954

Philadelphia 1939

Pittsburgh 1954

Scranton 1948

Sharon 1948

Williamsport

1953

$$
\begin{array}{r}
1 \% \\
1 \% \\
1 \% \\
1 / 2 \text { of } 1 \% \\
I / 2 \text { of } 1 \%
\end{array}
$$

$1 / 2$ of $1 \%$

$1 / 2$ of $1 \%$

$1 / 2$ of $1 \%$

$6 / 10$ of $1 \%$

$1 / 2$ of $1 \%$

$9 / 10$ of $1 \%$

$4 / 10$ of $1 \%$
$1 \%$
$1 \%$
$1 \%$
$1 / 4$ of $1 \%$
$1 / 2$ of $1 \%$
$1 \%$
$1 \%$
$11 \%$
$1 / 2$ of $1 \%$
$1 / 2$ of $1 \%$
$1 / 8$ of $1 \%$

a. $I / 2$ of $1 \%$ from October 1,1956 to December 31, 1956.

b. School district also imposes tax $1 / 4$ of $1 \%$.

Note: The Washington D.C. income tax is a progressive tax, and follows the pattern of state income taxes rather than the local flat rate taxes included here.

increases, governmental services are urgently needed. Many of these services necessitate large capital outlays; all involve substantial operating costs. Not only is there lacking the machinery of government necessary to do the job and the funds to do it with, but such governments as there are do not coincide in area with the functions to be performed and frequently lack the necessary legal powers.

The acute problems of many of these areas cannot wait upon determination of the proper governmental reforms to be effected and the political and public acceptance of those reforms. The achievement of annexation, consolidation, setting up a super unit of local government or any of the other possibilities that are being currently mentioned, is ordinarily a long, drawn-out process. Meanwhile, what is to be done?

Perhaps the most fruitful approach to answering this question is through an examination of what is actually being done. The most outstanding activity in this connection is the furnishing of such services 
to fringe areas by the central city. Already a considerable amount of this intergovernmental servicing is taking place, although by no means enough to take care of some critical situations. Moreover, the greatest disparity exists among different states and among different communities in the same state. Some helpful studies of such practices in certain states have recently been made, but an overall summary of the extent of these intergovernmental local services would involve a monumental study. Much more analysis of actual practices and much more critical evaluation of these practices by experienced governmental researchers would be timely and helpful.

The power to undertake such extraterritorial services by cities must, of course, stem from the state. In Alabama, municipalities apparently have exceptional leeway in this respect. Municipalities of 6,000 or more inhabitants may enforce police and sanitary ordinances and may levy business licenses within three miles of their corporate limits. Municipal planning commissions have planning, zoning and subdivision control powers in an area within five miles of the corporate limits. The Alabama cities may also provide fire service, water supply, sewerage and some other services beyond the corporate limits.

Water supply and fire service are perhaps the most frequent types of extraterritorial local services in most states. Various other types of service may be sold or given in certain areas. Procedures with respect to these services vary greatly. The central city may contract its services to satellite or county governments, or in the case of water supply, may sell them directly to individuals. There is great variation also in rates. Some services are performed without charge and many at a loss.

It is to the city's interest that the areas surrounding it be properly developed from the standpoint of land use, that they be provided with adequate water and sanitary facilities, that their traffic facilities permit an easy flow of traffic to and from the city, and that crime, fire and health hazards be kept under control.

The provision of many of these services cannot be handled adequately by small units. In many cases the central city can supply these services efficiently and economically. In doing so, however, there is no reason why the taxpaying residents of the central city should be penalized for the benefit of suburbanites who do not contribute to city support, as presently appears to be the case in a number of areas. The charges should be sufficient to pay all the costs of the service involved.

In addition to services that are performed in the fringe areas, suburbanites, as commuters and visitors to the central city, enjoy many 
of its services directly, usually without contributing at all to the support of the city.

\section{A TAx on the Urban Motorist}

An interesting new tax possibility for large cities which is beginning to be advocated is some form of special tax for the privilege of using city streets. Suggestions for such a tax are emanating from so many different quarters and are being advanced with so much frequency that it seems worth while for students of fiscal science to give the matter some very special attention. ${ }^{8}$

The rationale of the tax springs from the following considerations:

(1) The urban motorist involves the city in heavy financial costs:

(a) Because the provision and maintenance of city streets suitable for use by the modern motor car is an exceedingly costly enterprise;

(b) Because the regulation of traffic and other expenses caused by the motor car also add substantially to the city budget; and

(c) Because increasing use of private cars jeopardizes the solvency of mass transit operations and frequently involves the city in costly transit subsidies.

(2) The use of a motor car in a city is a sharply rationed privilege and not a right, since the amount of street space is not adequate to accommodate all persons, resident and nonresident, who might want to drive in the city. The more densely congested the city with multi-story dwelling places and places of employment, the more sharply limited is the privilege of driving in the city.

(3) The present rationing methods follow no logical pattern since they are not necessarily based either on the need to drive a car (e.g., in the case of doctors, salesmen and handicapped persons), on the willingness to pay for the privilege or even on being a local citizen and taxpayer. Instead, the streets may be, and apparently are, used to considerable extent by those who have sufficient time to suffer the traffic delays, by out-of-town visitors and by persons who are merely indulging in showmanship.

(4) The privilege of using the city street is at the expense of the non-motoring public and those who have cars but do not use them for city driving. In addition to paying for streets and

8. This proposal is discussed with no lack of sympathy for the motorist nor any lack of appreciation of his present burden on the part of the writer, who drives some 15,000 to 20,000 miles a year and whose decision to move from New York was originally sparked by the realization that Manhattan and the motor car are incompatible. 
other facilities for the motorist, such persons pay through time lost when they attempt to use other means of transportation, such as public transit, taxis and ambulances; through accidents; and through air pollution and noise.

Because of these considerations more and more persons are considering the advisability of a special tax upon urban motorists, preferably somewhat higher on the nonresident motorist.

Although the idea seems revolutionary at first glance, further consideration indicates that it may be the greatest boon to motorists since the advent of traffic lights. Probably every motorist feels a sense of irritation and frustration on being stopped by a red light. Nevertheless, a motorist is glad to have the safety of busy intersections protected in this way.

The average motorist already feels overburdened by charges and would undoubtedly strenuously oppose any special urban tax. But what the motorist wants is to be able to move. Being held up in one block while the traffic light shifts from red to green and back again some three or four times is a costly pastime.

If the deterrent of a motorist's privilege tax were coupled with the incentives to shift to mass transit that might be offered by abundant fringe parking facilities at moderate rates and serviced by mass transportation to the center of the city, a marked reduction in the number of motor cars used in the city might soon be evident. Such commuters and out-of-town visitors as presently bring their cars into the city, because suburban life necessitates starting their journey in them and there seems no presently satisfactory method of transferring from private car to public transportation on the outskirts of the city, would readily transfer. Many others who prefer to use their private cars would be influenced to make the shift because of the tax saving and the saving of parking and other charges in the city.

Both of these groups could readily avoid the tax by utilizing the suggested fringe parking facilities and mass transit, and it would not therefore be a burden to them. If such devices were sufficient to reduce by twenty or thirty per cent the number of cars entering the city, the motorists who continued, from necessity or choice, to drive their cars in the city would probably find that the value of their time that was thereby saved, plus the reduction in car operating costs due to more smoothly flowing traffic, would be far greater than the privilege tax.

Such a tax, if utilized by a city, would, however, have to be set sufficiently high to constitute a deterrent. Otherwise, it would be merely 
a nuisance and irritation, as is true of the present New York City use tax of five dollars per year on noncommercial vehicles of 3,500 pounds or less and ten per year on commercial vehicles and noncommercial vehicles over 3,500 pounds. Also, it would have to be devised so that it would fall upon nonresidents as well as residents. Some combination of annual fee for residents, coupled with an entrance fee, or toll, for nonresidents might be the most equitable.

Such a tax would be of financial benefit to the city in three ways: (a) by inducing motorists to shift to mass transit it would reverse the falling patronage trends of the transit lines that have resulted in heavy subsidies by many cities; (b) by decreasing traffic congestion in the streets the fiscal burden of coping with such congestion would be lessened; and, further, (c) it would provide a substantial amount of revenue to the central city, and like the payroll tax, it would extract a considerable portion of this revenue from nonresidents, who as commuters or contact population are benefiting from the city. The alternative seems likely to be increasingly rigid bans upon the use of motor cars in large cities. Such bans would injure most the persons whose need to use their cars was greatest.

\section{ReCapitulation}

The sources of revenue that have been discussed are not set forth as necessarily the most ideal in a theoretically ideal local government structure. Nor has there been any attempt to discuss every type of local tax presently being utilized by local governments. The large and important subject of state aid is likewise not covered. Rather the emphasis is on what the local governments can do to help themselves if they are granted sufficient taxing power by the states.

The revenue methods discussed above would probably go a long way toward eliminating tax controversies from consideration of governmental reorganization. Many controversial issues would still remain and the achievement of desirable changes would still continue to be difficult, but if any artificial tax advantages to central city or suburban fringe residents can be largely eliminated, it should be possible to focus attention more readily on other aspects of the problem.

The discussion has been limited to these four types of revenue because of their special pertinence for local governments in this transitional period when the established patterns of local population, trade and industrial development are giving way and we cannot be quite sure of what may be just around the corner. We are facing a new situation and new problems of great complexity. It is necessary that we make a new approach to local finance problems. 
In none of its parts does this presentation represent an original proposal. It is rather an effort to tie together the more advanced thinking of the persons who constitute the shock battalions grappling with these problems. In this sense it is believed that it represents a new-perhaps some will think a radical-approach. We can scarcely anticipate an ivory-tower solution of the fiscal problems of metropolitan regions. But throughout the country, officials and citizens are coming to grips with urgent problems. Much of their resultant action may be ill-advised, much may be sheer bungling, but here, there, and elsewhere, expedients are being devised as circumstances force action, and occasionally a workable device is found.

If those of us whose job it is to observe, record and analyze, can manage to keep abreast of these innumerable developments, it may be that out of this confusion, we shall be able to see emerging new principles and new solutions-not the inspired discovery or creation of any one person or group of persons, but rather solutions achieved through slow, painful forging by the repeated hammer blows of actual experimentation. 